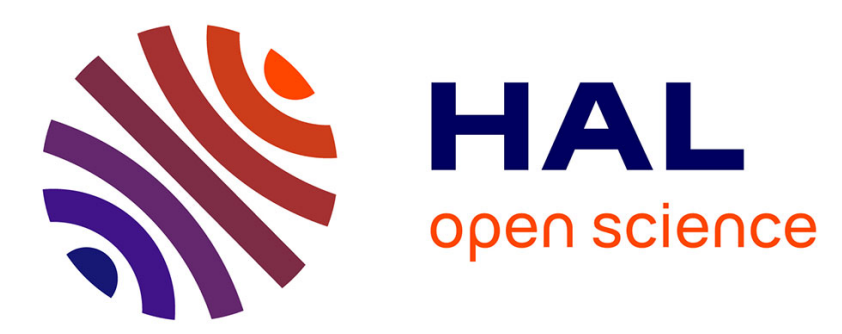

\title{
Evidence for sparse C-tactile afferent innervation of glabrous human hand skin
}

Roger Holmes Watkins, Mariama Dione, Rochelle Ackerley, Helena Backlund Wasling, Johan Wessberg, Line S Löken

\section{- To cite this version:}

Roger Holmes Watkins, Mariama Dione, Rochelle Ackerley, Helena Backlund Wasling, Johan Wessberg, et al.. Evidence for sparse C-tactile afferent innervation of glabrous human hand skin. Journal of Neurophysiology, 2021, 125 (1), pp.232 - 237. 10.1152/jn.00587.2020 . hal-03186723v2

\section{HAL Id: hal-03186723 \\ https://hal.science/hal-03186723v2}

Submitted on 11 Oct 2021

HAL is a multi-disciplinary open access archive for the deposit and dissemination of scientific research documents, whether they are published or not. The documents may come from teaching and research institutions in France or abroad, or from public or private research centers.
L'archive ouverte pluridisciplinaire HAL, est destinée au dépôt et à la diffusion de documents scientifiques de niveau recherche, publiés ou non, émanant des établissements d'enseignement et de recherche français ou étrangers, des laboratoires publics ou privés. 


\title{
Evidence for sparse C-tactile afferent innervation of glabrous human hand skin
}

\author{
Roger Holmes Watkins ${ }^{1,2}$, Mariama Dione ${ }^{1,2}$, Rochelle Ackerley ${ }^{1,2}$, Helena Backlund Wasling², Johan Wessberg², Line S. Löken²
}

${ }^{1}$ Aix Marseille Univ, CNRS, LNC (Laboratoire de Neurosciences Cognitives - UMR 7291), Marseille, France

${ }^{2}$ Department of Physiology, University of Gothenburg, Gothenburg, Sweden.

C-tactile (CT) afferents were long-believed to be lacking in humans, but were subsequently shown to densely innervate the face and arm skin, and to a lesser extent the leg. Their firing frequency to stroking touch at different velocities has been correlated with ratings of tactile pleasantness. CT afferents were thought to be absent in human glabrous skin; however, tactile pleasantness can be perceived across the whole body, including glabrous hand skin. We used microneurography to investigate mechanoreceptive afferents in the glabrous skin of the human hand, during median and radial nerve recordings. We describe CTs found in the glabrous skin, with comparable characteristics to those in hairy arm skin, and detail recordings from three such afferents. CTs were infrequently encountered in the glabrous skin and we estimate that the ratio of recorded CTs relative to myelinated mechanoreceptors (1:80) corresponds to an absolute innervation density of around 7 times lower than in hairy skin. This sparse innervation sheds light on discrepancies between psychophysical findings of touch perception on glabrous skin and hairy skin, although the role of these CT afferents in the glabrous skin remains subject to future work.

New \& Noteworthy: Human touch is encoded by low-threshold mechanoreceptors, including myelinated A $\beta$ afferents and unmyelinated C-tactile (CT) afferents. CTs are abundant in hairy skin and are thought to code gentle, stroking touch that signals positive affective interactions. CTs have never been described in human glabrous skin, yet we show evidence for their existence on the hand, albeit at relatively low density. Glabrous skin CTs may provide modulatory reinforcement of gentle tactile interactions during touch using the hands.

Innocuous touch in humans is primarily conveyed by low-threshold mechanoreceptive afferents, although the type and density differs across the body. In the glabrous (hairless) skin of the hands and feet, four types of lowthreshold mechanoreceptive afferents are found in humans (Johansson and Vallbo 1979a; Vallbo and Johansson 1984; Kennedy and Inglis 2002; Strzalkowski et al. 2018). These mechanoreceptors transmit information about conscious touch via fast-conducting, $A \beta$ myelinated fibers and, in human hairy skin covering the majority of the body, five types have been described (Vallbo et al. 1995), as well as low-threshold, unmyelinated C-fiber mechanoreceptive afferents, termed C-tactile (CT) afferents (Nordin 1990; Vallbo et al. 1993, 1999). A wealth of studies have investigated the myelinated mechanoreceptive afferents in glabrous hand skin (e.g. Hulliger et al. 1979; Johansson and Vallbo 1979b, 1979a; Johansson et al. 1980; Westling and Johansson 1987; Phillips et al. 1992; Birznieks et al. 2001; Johansson and Birznieks 2004; Pruszynski and Johansson 2014), but none have reported afferents resembling CTs.

Mechanoreceptive C-fiber afferents with high force activation thresholds (C-nociceptors) have been documented in glabrous hand skin, yet these have been difficult to find and not typically studied in microneurography, as intense stimulation is required for their activation/identification (Torebjörk and Ochoa 1990). However, C-nociceptors in hairy skin are encountered frequently with standard identification techniques (Nordin 1990; Vallbo et al. 1993, 1999; Watkins et al. 2017). This begs the question of whether CTs exist in glabrous skin, but are less easily found. Another reason why CTs may have remained elusive in glabrous hand microneurography experiments is the high density of readily identifiable lowthreshold, myelinated, $A \beta$ mechanoreceptive afferents, which have been the focus of most studies (e.g. Hulliger et al. 1979; Johansson and Vallbo 1979b, 1979a; Johansson et al. 1980; Westling and Johansson 1987; Phillips et al. 1992; Birznieks et al. 2001; Johansson and Birznieks 2004; Pruszynski and Johansson 2014). With the abundance of myelinated mechanoreceptive afferents, one may ask whether CT afferents, which convey relatively subtle tactile information (Olausson et al. 2002), could play a meaningful role in glabrous skin.

The physiological properties of $\mathrm{CT}$ afferents have provided the basis for the 'affective touch hypothesis', postulating a role for CTs in social bonding (Morrison et al. 2010; Olausson et al. 2010; McGlone et al. 2014). CT afferents optimally encode gentle, stroking touch delivered around skin temperature (Löken et al. 2009; Ackerley et al. 2014a), but relay this tactile information to the brain with a relatively long delay, providing a second wave of tactile information, after the first, rapid input from myelinated $A B$ mechanoreceptive afferents (Ackerley et al. 2013; Eriksson Hagberg et al. 2019). The firing frequency of CTs correlates with ratings of tactile pleasantness to skin stroking between $0.3-30 \mathrm{~cm} / \mathrm{s}$ (Löken et al. 2009; Ackerley et al. 2014a), where both measures show inverted-U shaped curves. Many psychophysical studies (see Croy et al. (2020) for a review) have demonstrated that the pleasantness curve is consistently found at a group level for stroking over the hairy arm skin. Psychophysical studies investigating pleasant stroking on the glabrous skin of the hand have found a flatter relationship in the palm than the arm, depending on the order of skin site stroked (Löken et al. 2011), or a relatively small difference between the hand and other body sites (Ackerley et al. 2014b). Therefore, the psychophysical evidence suggests that the relationship between pleasantness in the glabrous skin and the typical CT-firing curve is somewhat weaker.

Although no studies have reported evidence for CT-like afferents in human glabrous skin, a study by Nagi and Mahns (2013) proposed them to exist through indirect evidence, with animal work supporting this possibility. C-low-threshold mechanoreceptors (C-LTMs) are abundant in the hairy skin of animals and share many similarities to CTs, such as their low force activation threshold and unmyelinated axon (Abraira and Ginty 2013). Genetic mouse studies have shown that C-LTMs potentially innervate glabrous skin (Seal et al. 2009; Lou et al. 2013) and a study by Djouhri (2016) physiologicallycharacterized rare C-LTMs in rat glabrous skin (6\% of afferent C-fibers found) with a similar population reported in mice by Cain et al. (2001).

We make regular recordings from peripheral nerves that innervate both human hairy and glabrous skin, and have experience identifying CT afferents. Recordings in the superficial branch of the radial nerve identified a $\mathrm{CT}$ afferent with a receptive field on the dorsal aspect of the proximal phalanx of the third finger (Löken et al. 2007). Since we could not confirm this unit location as strictly glabrous, we do not include it here, yet it led us to examine potential CTs in glabrous skin during an experimental series that primarily investigated myelinated $A \beta$ mechanoreceptive afferents in the median nerve using microneurography. We aimed to characterize mechanosensitive C-fibers encountered in these recordings, to investigate their properties and prevalence in human glabrous skin.

\section{Material and Methods}

The data for the present work were collected in an experimental series involving median nerve recordings from 42 healthy human participants (age $26 \pm 6$ years, 10 males), with the CT data reported from two participants in this series (age 24 and 29 years, female and male, respectively). Another participant (age 24, male) from a separate experimental series was also included, where a CT was found in glabrous hand skin innervated by the radial nerve. All participants gave written, informed consent and were paid for their time. The study was approved by the local University of Gothenburg ethics committee and performed in accordance with the Declaration of Helsinki.

Participants were seated comfortably in a dentist's chair with their arm supported by a vacuum cast. In median nerve recordings, afferents in the palm and thumb were inaccessible for mechanical stimulation, due to the position of the hand. Standard microneurography techniques (Vallbo and Hagbarth 1968) were used to make recordings from the median and radial nerves, 8 and $4 \mathrm{~cm}$ proximal to the cubital fold respectively, both localized by electrical search procedures. Neural activity was recorded using high impedance, insulated tungsten microelectrodes (FHC, Bowdoin, ME) and sampled at either $16 \mathrm{kHz}$ (using Spike2, CED, Cambridge, UK; median nerve) or $12.8 \mathrm{kHz}$ (using Zoom/SC, University of Umeå, Umeå, Sweden; radial nerve).

Once an intraneural location was reached, the experimenter manually stroked the participant's hand/fingers whilst making small adjustments to the recording electrode to identify individual mechanoreceptive afferents. Afferents with cutaneous receptive fields were 
classified as either myelinated $A \beta$ or C-tactile (CT), in accordance with standard criteria (Vallbo and Johansson 1984; Vallbo et al. 1999); muscle/joint afferents were seen but not characterized. Sympathetic efferents (Macefield and Wallin 1996; Macefield et al. 2002) were encountered in the present recordings, and frequently responded to mechanical stimulation with a substantial delay (akin to C-fiber relative delays), but across multiple cutaneous regions, including the contralateral arm, and to generic arousal stimuli (e.g. a loud noise) (Delius et al. 1972; Hagbarth et al. 1972), so these responses were clearly distinct from afferent $\mathrm{C}$-fibers.

The mechanical threshold (lowest force consistently producing responses) was assessed at the most sensitive region of the receptive field using calibrated monofilaments. In the case of C-fibers, a soft sable brush was stroked across the receptive field to assess responses to a gentle mechanical stimulus (Vallbo et al. 1999; Watkins et al. 2017). Brief suprathreshold mechanical taps to the receptive field using a blunt $(1.5 \mathrm{~mm}$ diameter) plastic tip with force recording $(3.2 \mathrm{kHz})$ were used to estimate conduction velocity and a camera captured the timing of stimuli.

\section{Results}

Recordings were made from a total of three C-mechanoreceptive afferents projecting to the glabrous skin of the hand with physiological properties corresponding to CTs in three different participants, with receptive fields shown in Figure 1A. In median nerve experiments, two CTs were encountered with receptive fields in the glabrous skin of the fingers; at the radial side of the middle finger with no visible hair follicles present on this phalanx (unit 1; Fig. $1 \mathrm{~A}$ ) and at the base of the proximal phalanx of the index finger on the palmar side (unit 2; Fig. 1A). An additional CT in the palm was identified in the superficial cutaneous branch of the radial nerve and had its receptive field at the base of the thenar eminence, on the palmar side, several centimeters from any observable hair follicles (unit 3; Fig. 1A).

All CTs responded vigorously ( $>50$ spikes. $\mathrm{s}^{-1}$ ) to gentle mechanical stimulation, with a substantial delay (Fig. 1B,C,D), and the two median nerve CTs were calculated to have conduction velocities of 0.91 and $1.33 \mathrm{~m} . \mathrm{s}^{-1}$ based on mechanical tap response latencies, which correlate strongly with electrically-evoked latencies (Vallbo et al. 1999). All CT afferents had small, spot-like receptive fields and mechanical thresholds of $\leq 2.5 \mathrm{mN}(0.67$ and $2.5 \mathrm{mN}$ for the median nerve CTs and $2.5 \mathrm{mN}$ for the radial nerve $\mathrm{CT}$ ).
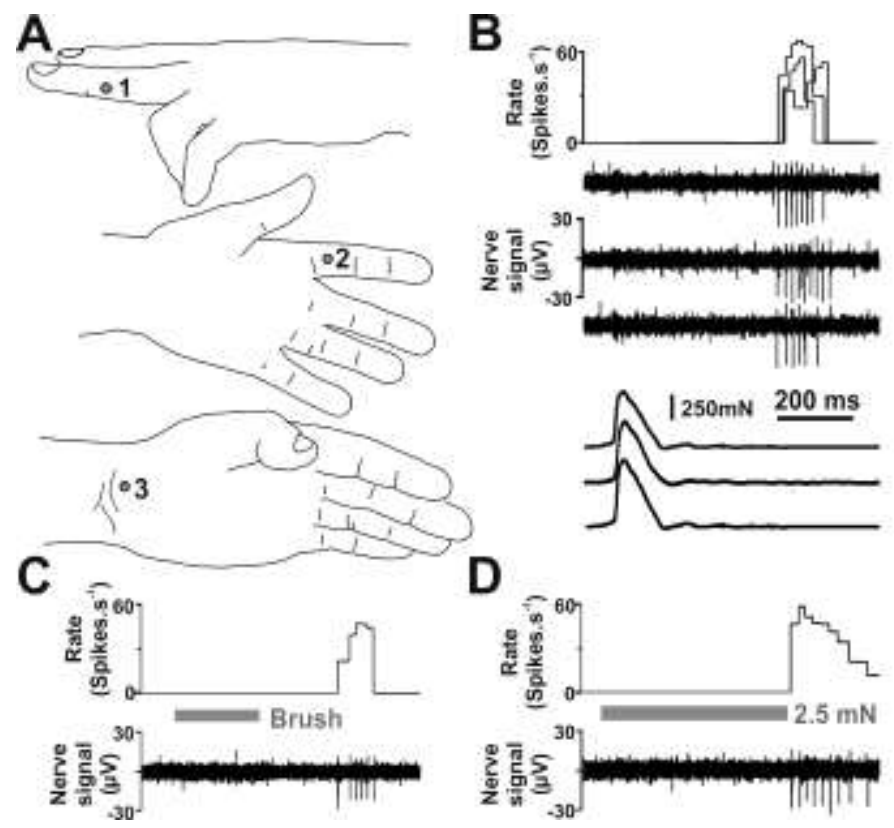

Figure 1: Receptive field locations and response properties of glabrous skin C-tactile (CT) afferents. (A) Schematic location of the center of CT receptive fields in the hand from median (unit 1 and 2) and radia (unit 3) nerve recordings. (B) Responses of a CT in glabrous skin (unit 1) to brief receptive field taps. Three subsequent, superimposed responses are aligned to the tap onset and consistent long-latency responses were evoked. Response of the same glabrous $\mathrm{CT}$ to $(\mathrm{C})$ a brush stroke over the receptive field and (D) 2.5 $\mathrm{mN}$ monofilament indentation; gray bars indicate stimulus timings, all timebases are the same as in (B).
We estimated the relative density of $C T$ afferents relative to $A \beta$ myelinated mechanoreceptive afferents by comparing the full number of mechanoreceptive afferents found in the median nerve experimental series. In 42 participants, we encountered 2 CTs and $161 \mathrm{~A} \beta$ mechanoreceptive afferents with receptive fields in the fingers. This gave a ratio of 1:80 for CTs to $A \beta$ mechanoreceptive afferents.

\section{Discussion}

The present report is the first study, to our knowledge, to identify afferent Cfibers with low mechanical thresholds in human glabrous skin. These were classed as CT afferents, based on the similarity to those found in hairy skin (cf. Nordin 1990; Vallbo et al. 1999; Watkins et al. 2017). A wealth of previous studies in glabrous skin (recordings made at the same median nerve location as the present study, e.g. Hulliger et al. 1979; Johansson and Vallbo 1979a, 1979b; Johansson et al. 1980; Westling and Johansson 1987; Phillips et al. 1992; Birznieks et al. 2001; Johansson and Birznieks 2004; Oddo et al. 2011) have not reported this population of afferents. A plausible explanation for this discrepancy is that these afferents are rare and their responses can resemble sympathetic efferent C-fiber responses to arousal from mechanical stimulation (Hagbarth et al. 1972). Additionally, a detailed knowledge of the physiological properties of CT afferents, only documented in humans around 20 years ago, makes it easier to differentiate and identify these afferents when recording. Thus, it is possible these afferents were encountered during recordings previously, but were not the main aim of the research and therefore overlooked.

The median nerve mainly projects to the volar glabrous hand skin but it also innervates the distal dorsal fingers (representing 5\% of the median innervation at the wrist (Johansson and Vallbo 1979a)) and the lateral aspects of the fingers, which are transitional skin. Out of the two median nerve CT units identified presently, one was clearly on volar glabrous skin (unit 2) and the other was on lateral glabrous finger skin, but distant from any hair follicles (unit 1). The cutaneous innervation of the radial nerve is predominantly to the hairy dorsum hand skin, but the location of the unit identified here suggests this was located in one of the glabrous skin fascicles innervating the thenar eminence (Campero et al. 2005). Therefore, all CTs presented in the current work likely originated from glabrous skin innervating fascicles. Further work using alternative identification techniques and at different recording sites (e.g. upper arm/wrist, glabrous skin of the feet), may address the CT innervation pattern and how it relates to that of $A \beta$ mechanoreceptive afferents (Johansson and Vallbo 1979a), which may help in elucidating the functions of these different afferents.

The physiological properties of our glabrous CTs correspond well to CTs in hairy skin (low mechanical thresholds, spot like receptive fields, vigorous responses to gentle mechanical stimulation; Nordin 1990; Vallbo et al. 1999; Wessberg et al. 2003; Watkins et al. 2017). The response characteristics of CTs in the present study differentiated them from even the lowest threshold C-nociceptive afferents in hairy skin (Nordin 1990; Vallbo et al. 1999; Watkins et al. 2017). As C-nociceptive afferents in glabrous skin have substantially higher mechanical thresholds (Torebjörk and Ochoa 1990), these would be readily separable from the low-threshold C-fibers described in the present study.

We presently had an occurrence ratio of 1:80 for CTs to myelinated $A \beta$ mechanoreceptive afferents in the glabrous skin of the index, middle, and ring fingers. Vallbo et al. (1993) found that CTs were frequently encountered in the forearm, constituting $40 \%$ of the units sampled, although Edin (2001) found an incidence of $\sim 10 \%$ in the thigh skin. We have attempted to estimate the relative density of CTs in the glabrous skin compared to hairy skin, which has proportionally fewer myelinated $A \beta$ mechanoreceptive afferents (McGlone et al. 2014). Tactile acuity, which relates to myelinated $A \beta$ mechanoreceptor innervation density, is approximately 10 times higher on the fingers than the arm, suggesting a 10 fold innervation density difference (Weinstein 1968; Vallbo and Johansson 1984). Estimates from microneurography recordings indicate slowly-adapting type 1 innervation density is 8 times higher in the fingers than the arm, corresponding to 11 times higher for all myelinated $A \beta$ mechanoreceptors when correcting for the slightly different proportions in each region (Johansson and Vallbo 1979a; Vallbo et al. 1995). Therefore, taking into account the relative difference in innervation density of the myelinated $A \beta$ mechanoreceptive afferents between the fingers and the arm, the relative frequency of CT afferent recordings in the glabrous hand vs. hairy arm skin (1:80 vs 1:1) still suggests a 
lower density of $\mathrm{CT}$ afferent innervation of the glabrous skin than $\mathrm{CT}$ innervation of hairy skin, by a factor of $\sim 7$.

Low glabrous skin CT innervation density may help explain some of the psychophysical observations and discrepancies of sensations in glabrous vs. hairy skin. The relationship between CT firing frequency and perceived pleasantness is not a direct "labeled line", as the perception of pleasantness is a consequence not only of bottom-up neural signals, but also of central processing (Löken et al. 2009), with influence from previous experience, situational context, and expectations, as well as co-processing with input from other sensory channels. For example, there is high inter-individual variability in the pleasantness curve (Croy et al. 2020), which is subject to change under different conditions (e.g. touch at different temperatures, Ackerley et al. (2014a), multisensory interactions with odor, Croy et al. (2014)). Likewise, stroking over the glabrous palm skin is pleasant, although the quadratic bending of the psychophysical response curve is weaker than on hairy skin (Löken et al. 2011; Ackerley et al. 2014b). Furthermore, A $B$ mechanoreceptive afferents are vital for the conscious perception of touch, while CTs likely do not convey conscious tactile sensations (rare neuronopathy patients who lack myelinated afferents do not consciously feel touch, Olausson et al. (2002)) and patients with reduced $\mathrm{C}$-fiber innervation rate pleasant tactile sensations similar to neurotypical participants, albeit at a lower magnitude (Morrison et al. 2011). This indicates important roles for both $C T$ and myelinated $A \beta$ mechanoreceptive afferents in signaling innocuous touch and that both likely contribute to pleasantness (Eriksson Hagberg et al. 2019).

A clear limitation of our study is the low number of CTs encountered; hence, the calculations of comparative innervation density are approximate. It also remains to be seen if these afferents share other properties of CTs in hairy skin, such as velocity tuning (Löken et al. 2009; Ackerley et al. 2014a) and electrically-defined axonal properties (Watkins et al. 2017), as physiological differences are seen between glabrous and hairy skin C-nociceptors (Torebjörk and Ochoa 1990). For future studies of CTs in glabrous skin, standard single unit microneurography techniques are unlikely to be successful, due to the very low yield. However, if complemented with electrical classification techniques (Serra et al. 1999; Watkins et al. 2017; Ackerley and Watkins 2018), these afferents may be identifiable in population recordings to allow further study. This may facilitate additional experiments on these glabrous CT afferents assessing their innervation pattern and differentiation of functional properties, particularly with respect to the glabrous skin C-nociceptors using thermal/chemical stimulation (e.g. Schmelz et al., 2003) and electrical stimulation (Watkins et al. 2017).

The glabrous skin of the hand serves a very different function to that of our hairy skin, as it is used for tactile exploration, surface/object identification, and complex motor tasks, whereas the hairy skin is more involved in the reception of touch (McGlone et al. 2007; Ackerley and Kavounoudias 2015). One may ask, what is the functional role of CTs in glabrous skin? Glabrous skin CTs may provide an sub-conscious modulatory reinforcement of gentle touch signals from the conscious, discriminative fastinput from myelinated mechanoreceptors, and Nagi and Mahns (2013) postulated that CTs existed in glabrous hand skin and could mediate mechanical allodynia, potentially playing a protective role after tissue injury. The lower density of CT afferents in glabrous skin may mean their activity influences tactile perception less than in hairy skin, which is consistent with psychophysical findings. The present work provides evidence for the existence of CTs in glabrous hand skin, but their functional role is yet to be uncovered. Knowledge of their existence and their comparatively low density will allow future studies to address this.

\section{Acknowledgments}

We thank Karin Göthner for excellent technical assistance. This study was supported by Swedish Research Council (grant 2017-01717 to J. Wessberg), European Union FP7 Project PROTOTOUCH (grant agreement 317100), and EU Horizon 2020 Project DeTOP (grant agreement 687905) and by Åke Wiberg Foundation (grant M17-0190 to L. Löken).

\section{Post-print version}

Post-print (accepted version, not publisher format) of the paper made in 2021 by R. Ackerley for submission to the HAL open archive

https://hal.archives-ouvertes.fr/

\section{References}

Abraira VE, Ginty DD. The sensory neurons of touch. Neuron 79: 618-39, 2013.

Ackerley R, Backlund Wasling H, Liljencrantz J, Olausson H, Johnson RD, Wessberg $\mathrm{J}$. Human $\mathrm{C}$-tactile afferents are tuned to the temperature of a skinstroking caress. J Neurosci 34: 2879-83, 2014a.

Ackerley R, Carlsson I, Wester H, Olausson H, Backlund Wasling H. Touch perceptions across skin sites: differences between sensitivity, direction discrimination and pleasantness. Front Behav Neurosci 8: 54, 2014b.

Ackerley R, Eriksson E, Wessberg J. Ultra-late EEG potential evoked by preferential activation of unmyelinated tactile afferents in human hairy skin. Neurosci Lett 535: 62-66, 2013.

Ackerley R, Kavounoudias A. The role of tactile afference in shaping motor behaviour and implications for prosthetic innovation. Neuropsychologia 79: 192-205, 2015.

Ackerley R, Watkins RH. Microneurography as a tool to study the function of individual C-fiber afferents in humans: responses from nociceptors, thermoreceptors, and mechanoreceptors. J Neurophysiol 120: 2834-2846, 2018.

Birznieks I, Jenmalm P, Goodwin AW, Johansson RS. Encoding of direction of fingertip forces by human tactile afferents. J Neurosci 21: 8222-37, 2001.

Cain DM, Khasabov SG, Simone DA. Response properties of mechanoreceptors and nociceptors in mouse glabrous skin: An in vivo study. J Neurophysiol 85: 1561-1574, 2001.

Campero M, Serra J, Ochoa JL. Peripheral projections of sensory fascicles in the human superficial radial nerve. Brain 128: 892-5, 2005.

Croy I, Bierling A, Sailer U, Ackerley R. Individual Variability of Pleasantness Ratings to Stroking Touch Over Different Velocities. Neuroscience ( March 26, 2020). doi: 10.1016/j.neuroscience.2020.03.030.

Croy I, D'Angelo S, Olausson H. Reduced pleasant touch appraisal in the presence of a disgusting odor. PLoS One 9: e92975, 2014.

Delius W, Hagbarth K -E, Hongell A, Wallin BG. Manoeuvres Affecting Sympathetic Outflow in Human Skin Nerves. Acta Physiol Scand 84: 177-186, 1972.

Djouhri L. Electrophysiological evidence for the existence of a rare population of C-fiber low threshold mechanoreceptive (C-LTM) neurons in glabrous skin of the rat hindpaw. Neurosci Lett 613: 25-29, 2016.

Edin B. Cutaneous afferents provide information about knee joint movements in humans. J Physiol 531: 289-97, 2001.

Eriksson Hagberg E, Ackerley R, Lundqvist D, Schneiderman J, Jousmäki V, Wessberg J. Spatio-temporal profile of brain activity during gentle touch investigated with magnetoencephalography. Neuroimage 201: 116024, 2019. Hagbarth K -E, Hallin RG, Hongell A, Torebjörk HE, Wallin BG. General Characteristics of Sympathetic Activity in Human Skin Nerves. Acta Physiol Scand 84: 164-176, 1972.

Hulliger M, Nordh E, Thelin A-EE, Vallbo ÅB. The responses of afferent fibres from the glabrous skin of the hand during voluntary finger movements in man. J Physiol 291: 233-249, 1979.

Johansson RS, Birznieks I. First spikes in ensembles of human tactile afferents code complex spatial fingertip events. Nat Neurosci 7: 170-7, 2004.

Johansson RS, Vallbo AB. Tactile sensibility in the human hand: relative and absolute densities of four types of mechanoreceptive units in glabrous skin. $J$ Physiol 286: 283-300, 1979a.

Johansson RS, Vallbo AB. Detection of tactile stimuli. Thresholds of afferent units related to psychophysical thresholds in the human hand. J Physiol 297: 405-22, 1979b.

Johansson RS, Vallbo AB, Westling G. Thresholds of mechanosensitive afferents in the human hand as measured with von Frey hairs. Brain Res 184: 343-51, 1980.

Kennedy PM, Inglis JT. Distribution and behaviour of glabrous cutaneous receptors in the human foot sole. J Physiol 538: 995-1002, 2002.

Löken LS, Evert M, Wessberg J. Pleasantness of touch in human glabrous and hairy skin: order effects on affective ratings. Brain Res 1417: 9-15, 2011.

Löken LS, Wessberg J, Morrison I, McGlone F, Olausson H. Coding of pleasant touch by unmyelinated afferents in humans. Nat Neurosci 12: 547-8, 2009.

Löken LS, Wessberg J, Olausson HW. Unmyelinated tactile (CT) afferents are present in the human peroneal and radial nerves. In: Soc Neurosci Abstrs. 2007, p. 827.2.

Lou S, Duan B, Vong L, Lowell BB, Ma Q. Runx1 controls terminal morphology and mechanosensitivity of VGLUT3-expressing C-mechanoreceptors. J 
Neurosci 33: 870-82, 2013.

Macefield VG, Elam M, Wallin BG. Firing properties of single postganglionic sympathetic neurones recorded in awake human subjects. Auton Neurosci Basic Clin 95: 146-159, 2002.

Macefield VG, Wallin BG. The discharge behaviour of single sympathetic neurones supplying human sweat glands. J Auton Nerv Syst 61: 277-286, 1996.

McGlone F, Vallbo AB, Olausson H, Löken L, Wessberg J. Discriminative touch and emotional touch. Can J Exp Psychol 61: 173-183, 2007.

McGlone F, Wessberg J, Olausson $\mathbf{H}$. Discriminative and affective touch: sensing and feeling. Neuron 82: 737-55, 2014.

Morrison I, Löken LS, Minde J, Wessberg J, Perini I, Nennesmo I, Olausson H. Reduced C-afferent fibre density affects perceived pleasantness and empathy for touch. Brain 134: 1116-26, 2011.

Morrison I, Löken LS, Olausson H. The skin as a social organ. Exp brain Res 204: 305-14, 2010.

Nagi SS, Mahns D a. Mechanical allodynia in human glabrous skin mediated by low-threshold cutaneous mechanoreceptors with unmyelinated fibres. Exp brain Res 231: 139-51, 2013.

Nordin M. Low-threshold mechanoreceptive and nociceptive units with unmyelinated (C) fibres in the human supraorbital nerve. J Physiol 426: 229240, 1990.

Oddo CM, Beccai L, Wessberg J, Wasling HB, Mattioli F, Carrozza MC. Roughness encoding in human and biomimetic artificial touch: spatiotemporal frequency modulation and structural anisotropy of fingerprints. Sensors 11: 5596-615, 2011.

Olausson H, Lamarre Y, Backlund H, Morin C, Wallin BG, Starck G, Ekholm S, Strigo I, Worsley K, Vallbo AB, Bushnell MC. Unmyelinated tactile afferents signal touch and project to insular cortex. Nat Neurosci 5: 900-4, 2002.

Olausson H, Wessberg J, Morrison I, McGlone F, Vallbo A. The neurophysiology of unmyelinated tactile afferents. Neurosci Biobehav Rev 34: 185-91, 2010.

Phillips JR, Johansson RS, Johnson KO. Responses of human mechanoreceptive afferents to embossed dot arrays scanned across fingerpad skin. J Neurosci 12: 827-39, 1992.

Pruszynski JA, Johansson RS. Edge-orientation processing in first-order tactile neurons. Nat Neurosci 17: 1404-9, 2014.

Schmelz M, Schmidt R, Weidner C, Hilliges M, Torebjork HE, Handwerker HO. Chemical response pattern of different classes of $\mathrm{C}$-nociceptors to pruritogens and algogens. J Neurophysiol 89: 2441-8, 2003.

Seal RP, Wang X, Guan Y, Raja SN, Woodbury CJ, Basbaum AI, Edwards RH. Injury-induced mechanical hypersensitivity requires C-low threshold mechanoreceptors. Nature 462: 651-5, 2009.

Serra J, Campero M, Ochoa J, Bostock H. Activity-dependent slowing of conduction differentiates functional subtypes of $\mathrm{C}$ fibres innervating human skin. J Physiol 515: 799-811, 1999.

Strzalkowski NDJ, Peters RM, Inglis JT, Bent LR. Cutaneous afferent innervation of the human foot sole: what can we learn from single-unit recordings? J Neurophysiol 120: 1233-1246, 2018.

Torebjörk HE, Ochoa JL. New method to identify nociceptor units innervating glabrous skin of the human hand. Exp Brain Res 81: 509-514, 1990.

Vallbo Å, Hagbarth K. Activity from skin mechanoreceptors recorded percutaneously in awake human subjects. Exp Neurol 289: 270-289, 1968.

Vallbo Å, Olausson $\mathbf{H}$, Wessberg $\mathbf{J}$. Unmyelinated afferents constitute a second system coding tactile stimuli of the human hairy skin. $J$ Neurophysiol 81: 2753-2763, 1999.

Vallbo A, Olausson $\mathbf{H}$, Wessberg J, Norrsell U. A system of unmyelinated afferents for innocuous mechanoreception in the human skin. Brain Res 628: 301-4, 1993.

Vallbo AB, Johansson RS. Properties of cutaneous mechanoreceptors in the human hand related to touch sensation. Hum Neurobiol 3: 3-14, 1984.

Vallbo AB, Olausson H, Wessberg J, Kakuda N. Receptive field characteristics of tactile units with myelinated afferents in hairy skin of human subjects. $J$ Physiol 483: 783-95, 1995.

Watkins RH, Wessberg J, Wasling HB, Dunham JP, Olausson H, Johnson RD, Ackerley R. Optimal delineation of single C-tactile and C-nociceptive afferents in humans using latency slowing. J Neurophysiol 117: 1608-1614, 2017.

Weinstein S. Intensive and extensive aspects of tactile sensitivity as a function of body part, sex and laterality. In: The Skin Senses, edited by Kenshalo D. Springfield, IL: Charles C. Thomas, 1968, p. 192-222.
Wessberg J, Olausson H, Fernström KW, Vallbo AB. Receptive field properties of unmyelinated tactile afferents in the human skin. J Neurophysiol 89: 156775, 2003.

Westling G, Johansson RS. Responses in glabrous skin mechanoreceptors during precision grip in humans. Exp Brain Res 66: 128-40, 1987. 